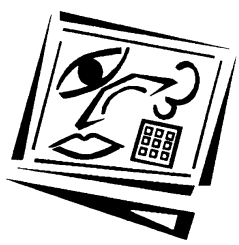

\title{
Preferences for deep-surface learning: A vocational education case study using a multimedia assessment activity
}

\author{
Simon Hamm \\ William Angliss TAFE \\ Ian Robertson \\ RMIT University
}

\begin{abstract}
This research tests the proposition that the integration of a multimedia assessment activity into a Diploma of Events Management program promotes a deep learning approach. Firstly, learners' preferences for deep or surface learning were evaluated using the revised two-factor Study Process Questionnaire. Secondly, after completion of an assessment exercise comprising a multimedia presentation with digital images and oral commentary, the respondents' self-described approaches to learning were collected using semi-structured interviews. Using these two data sets, learners preferred and implemented learning approaches were compared. Results show that whilst the multimedia assessment exercise did not prohibit the adoption of a deep learning approach, it tended to enable the adoption of both deep and surface learning approaches. In addition to informing our understanding of the relationship between deep and surface learning preferences and the implementation of a multimedia assessment item, the data gathered also provide some clues related to the sorts of factors that the respondents considered and how they responded to these factors in their undertaking of the assessment exercise.
\end{abstract}

\section{Introduction}

The small scale research project reported here is a response to the observation that there is a lack of empirical evidence to substantiate the enthusiasm with which some commentators promote the benefits of digital technology in enhancing learning. Specifically, the paper documents research that sought to test the proposition that the integration of a multimedia assessment activity into a Diploma of Events Management program would promote a deep learning approach. The research was conducted at a metropolitan TAFE provider which is a part of the broader Australian vocational education and training (VET) sector.

Data were collected from thirteen students enrolled in the second year of a Diploma in Events Management who had been required to complete a multimedia assessment activity on the topic of occupational health and safety in the workplace. Using a digital camera, participants produced 10 to 20 relevant digital images. Using Microsoft Photostory these images were compiled with pre-recorded music and a commentary into a two to three minute multimedia presentation. 
Two sources of data were collected. Firstly, the Revised Two-Factor Study Process Questionnaire (R-SPQ-2F ) (Biggs, Kember \& Leung, 2001) was conducted as a measure of participant's preference for deep or surface learning. The results of this survey were used as a benchmark against which to compare the findings of semi-structured interviews which asked questions about student's self-perceived learning preference, and the approach that they took in completing the multimedia assessment task.

\section{Literature survey}

This literature survey is divided into three major sections. Firstly, learning styles and preferences and their measurement, with an emphasis on deep and surface learning, are considered. Secondly, given the age profile of the respondent group, the claimed characteristics of the Net generation or digital natives are reported and examined. Finally, assessment approaches in TAFE with an emphasis on multimedia assessment items is briefly considered.

\section{Learning styles}

The use of the terms learning styles, learning preferences and learning strategies are often confusing and ambiguous. Sadler-Smith and Smith (2004) provide useful guidance in this regard. Learning styles reflect the intrinsic, habitual way that a learner acquires information, skills and knowledge. 'Most simply conceived, learning style is the typical way an individual likes to go about learning' (Smith \& Dalton, 2005, p.5). Learning preferences relate to the learner's bias towards a distinct teaching and learning method. Learning strategy relates to the particular method or approach that the learner prefers to use in negotiating a learning activity or process.

Coffield, Mosely, Hall and Ecclestone (2004) describe the field of research into learning styles as lacking unification. In a comprehensive review they identify five families of learning style analysis based on theoretical origins, pedagogical foundations and commercial bias. These families also reflect the stability, predictability or flexibility of the approach that the student adopts. The R-SPQ-2F which is used in the current research is consistent with the fifth category described by Coffield et al (2004). That is a flexible, stable learning model. This category targets the strategies and approaches that students' adopt in relation to information and learning processes. Initially derived from empirical observation of how students approached study, the idea of deep and surface learning approaches was proposed by Marton and Saljo (1976a, 1976b). Those students adopting a deep approach focussed on understanding whilst those adopting a surface approach aimed at memorisation. In the UK, Entwistle (1981) built on the idea of deep and surface learning, identifying a third (strategic) approach that aimed at high achievement using either the deep or surface approach as required (Case \& Marshall, 2009). This approach is no longer recognised as a distinct learning approach (Case \& Marshall, 2009) and is not evaluated in the R-SPQ-2F . In Australia, Biggs also adopted and developed the ideas of deep and surface learning (Case \& Marshall, 2009).

Ramsden (1988) puts the difference between surface and deep learning simply by stating that deep learning is more about understanding and the surface approach more about memorisation. Key characteristics of deep and surface learning can be summarised as follows. 
Table 1: Characteristics of deep and surface learning

\begin{tabular}{|l|l|l|}
\hline & \multicolumn{1}{|c|}{ Deep learners tend to .... } & \multicolumn{1}{c|}{ Surface learners tend to ... } \\
\hline Time and effort & $\begin{array}{l}\text { Go beyond what is required for } \\
\text { assessment } \\
\text { Spend time and effort on learning }\end{array}$ & $\begin{array}{l}\text { Do just enough to complete the } \\
\text { assessment } \\
\text { Spend only the time required to meet } \\
\text { minimum requirements }\end{array}$ \\
\hline Questions asked & Ask why not just how & Asks how rather than why \\
\hline Level of research & Thoroughly researches the task & Uses information provided \\
\hline $\begin{array}{l}\text { Impact of } \\
\text { assessability }\end{array}$ & $\begin{array}{l}\text { Spend time and effort on topics even } \\
\text { though they are not assessed }\end{array}$ & Focus on assessable tasks only \\
\hline Cognitive effort & Aim at understanding & Aim at memorisation, rote learning \\
\hline $\begin{array}{l}\text { Importance of } \\
\text { personal interest }\end{array}$ & $\begin{array}{l}\text { Aims to satisfy curiosity and personal } \\
\text { interest but will pursue topics of less } \\
\text { personal interest }\end{array}$ & $\begin{array}{l}\text { Spend a greater amount of time on } \\
\text { topics of personal interest }\end{array}$ \\
\hline
\end{tabular}

Importantly, the deep/surface learning approach does not categorise students as deep or surface learners. Whilst learners are likely to have a preference for either a deep or surface learning approach, the enacted approach is not fixed but subject to variation depending on a number of intrinsic and extrinsic factors. This is reflected in the Biggs et al., (2001, p.136) presage, process and product (3P) model and Ramsden's (2003 cited in Richardson, 2004) student learning in context. These models identify: pre-existing characteristics such as ability, previous educational experience orientation to study; the context of learning such as teaching approach, objectives/curriculum, assessment, climate/ethos, institutional procedures) as important in shaping the learner's approach to learning.

For example, high workload, unclear goals and a focus on examinations promote a surface learning approach; support, structure and cohesion, a focus on metacognitive development and independent learning are likely to promote a deep learning approach. However, there have been few attempts to provide empirical evidence that alterations in the context of learning will promote a deep learning approach (Case \& Marshall, 2009).

Over time a number of surveys designed to evaluate deep and surface learning approaches have been developed (Case \& Marshall, 2009). Here the R-SPQ-2F was chosen because it is widely used in education (Richardson, 2004) and provides a relatively simple and quick method to evaluate the learner's preference for surface or deep learning. Although there continue to be discussions about the validity of such questionnaires (Coffield, et al., 2004; Richardson, 2004), the survey has been validated (Biggs, et al., 2001) and replicated by others (Mimirinis \& Bhattacharya, 2007).

It is reasonable to assert that there is an assumption that educational contexts should promote deep rather than surface learning and this is reflected in the few reports that attempt to change learner's approaches. For example, Biggs et al., (2001, p.136) state that '.... the generic aim of good teaching is precisely to encourage students to adopt a deep approach and to discourage the use of a surface approach'. Cope and Staehr (2005) attempted to increase the proportion of students using deep learning approaches over a five year period. At the conclusion of each year, small scale changes associated with structure, assessment and workload were made to the structure of an undergraduate course in information technology. Different cohorts were surveyed each year over the five year period. The authors conclude that there was no change in the proportion of students using deep learning approaches over the first four years, 
but that there was a statistically significant increase in the proportion of learner's using aspects of deep learning approaches in the fifth year. These results are not convincing, the authors qualify their findings by stating that 'research is needed to confirm that the results for 2002 [the fifth year] were not a one-off, and a consequence of factors external to the subject' (Cope \& Staehr, 2005, p.194).

Research into deep and surface learning also recognises the phenomenon of 'dissonance'. That is 'illogical relationships between approaches to learning and perceptions of context' (Case \& Marshall, 2009, p.14). Given that the current research used the R-SPQ-2F to evaluate the respondents predicted learning approach, and semistructured interviews were used to evaluate the actual approach taken in completing the multimedia assessment item, in this case dissonance also relates to a lack of confluence between the predicted and enacted approach to learning. In a study involving a survey of 110 law students and oral or written comments from 64 of these respondents Lindblom-Ylanne (2003) concluded that coherence and dissonance is not a simple construct but varied from clearly coherent to clearly dissonant on a continuum with some students demonstrating slight or unclear dissonance. They propose that this is the result of either a lack of metacognitive skills or 'a destructive friction between these students and their learning environment [which often] forced them to study more superficially than they would normally do' (Lindblom-Ylanne, 2003, p.76). This reflects the proposition that dissonance 'is characterised by an atypical combination of aspects of studying, which do not theoretically fit together' (Lindblom-Ylanne, 2003, p.63) as may be the case where there is incongruence between the teacher's teaching strategies and the learner's learning strategies.

\section{Generational preferences and digital technology}

The age of the respondents in the current research ranges from 19 to 25 years old, they were born between 1983 and 1991. This means that all respondents fall into the generational group commonly identified as Generation Y, the NET Generation (Oblinger \& Oblinger, 2005) or digital natives (Prensky, 2001). This group has grown up with and may never have known life without information technology.

The promotion of technology in education, particularly as it relates to this generation, appears to be underpinned by the three related assumptions. Firstly, that Generation $Y$ has a preference for the use of technology for educational purposes. Secondly, that Generation $Y$ thinks and learns differently from previous generations and thirdly that Generation $Y$ has the skill set required to productively use technology for educational purposes. These three assumptions also have consequences for our VET learners in this study, relating to a contentious preference for and readiness skills to be successful in technology-based learning.

Prensky (2007, p.41) asserted that 'students are clamouring to these technologies to be used as part of their education'. Advocates of the use of digital technology such as Oblinger and Oblinger (2005) describe Generation Y as primarily visual and kinaesthetic learners who prefer immediacy and multitasking, collaboration and experiential learning about 'things that matter'. Such assertions lack a strong empirical base (Bennett, Maton \& Kervin, 2008). For example, using the Soloman and Felder learning style inventory with bank employees across the generations, Doumani (2008) concluded that there were no large differences across the generations, and that the similarities outweighed the differences. 
In respect to a preference for technology based education, in the USA, Kvavik (2005) found a moderate rather than high demand for the use of technology. In Australia, Becker, Kehoe and Tennant (2007) found that undergraduate students preferred a mix of print and web-based materials rather than only online/web materials. With respect to university students, these findings are further supported by Kennedy, Judd, Churchward, Gray \& Krause (2008) who argue that there is no clear universality between being at a generational milestone (Generation $Y$ rather than Generation $X$ ) and having a predilection for the latest cutting edge technology.

Concerning the ability of generation $Y$ to use technology for learning, the literature is also ambivalent about the veracity of such an assumption. For example, Bennett et al (2008, pp.778-779) find that whilst 'a proportion of young people are highly adept with technology ... there also appears to be a significant proportion of young people who do not have the levels of access or technology skills predicted by proponents of the digital native idea'. This conclusion reinforces the findings by MCEETYA (2007) which conducted a national assessment of the ICT literacy of 7400 students across Australia in October 2005.

\section{Digital multimedia development as assessment in vocational education}

Both digital storytelling and the multimedia assessment item developed in the research reported here combine visual and audio elements into a digital file to create an audiovisual presentation. What differs between the two approaches is the intention and output. In the case of digital storytelling, learners typically are creating personal narratives based around personal experiences. In the case of the learner developed multimedia assessment item produced in the current research, the digital multimedia product is vocationally orientated. In this research learners produced an assessment task based around the context of occupational health and safety within a workplace.

In the context of schools, Ohler (2009) supports the benefits of digital storytelling in assisting learners to be more creative, and to engage in a deeper, critical level of thinking. In respect to digital storytelling in schools, Kajder \& Swenson (2004) highlight that the acceptance of technology has helped liberate the creative and dynamic potential of learners, thus allowing for greater developmental and artistic work to be achieved. This, the authors maintain, engenders a confidence and motivation in learners that was not previously exhibited. Sadik (2008) stresses the layered nature of digital storytelling and its ability to incorporate an almost remedial benefit for learners struggling in areas such as reading, writing and aural skills.

There are also those who see digital storytelling in a more sceptical light. According to Moon (2006), digital storytelling does not address complex, ingrained and even dysfunctional learning habits developed over a long period in the schooling system. Some authors are also critical of the dependency on electronic educational tools as a means to engage the learner. They caution against an over-emphasis of concern for the technology to the detriment of content, creativity and originality (Bauerlein, 2006; Woodward \& Nanlohy, 2004).

Whilst digital storytelling has been promoted in the VET sector since 2002 (McGrath \& Patetl, 2002), there is limited academic commentary on this approach. In a conference paper, Jay and Connors (2005) asserted that the added use of visuals and music create a rich, personal and unique body of work as part of their overall assessment. Consistent with the lack of commentary on digital storytelling in the VET and 
university sectors, our survey of recent publications also reveals that there is a paucity of commentary on the use of learner developed multimedia for assessment, as used in the current research.

In the only reference that we can find that relates to assessment using multimedia created by learners, Cox, Vasconcelos and Holdridge (2008) describe and evaluate the development and assessment of visual presentations by undergraduate students. This research complements but is different from the work reported here. Where Cox, Vasconcelos and Holdridge (2008) draw conclusions about the quality of multimedia presentations, the level of learner engagement, copyright issues and the equity of this technology based approach, our research is concerned with the deep and/or surface learning styles adopted by participants who completed a multimedia assessment item.

\section{Method}

Following ethics approval from the institution involved in this research, a plain language statement was circulated to a possible 180 participants involved in the second year of the Diploma in Events Management. Of these, thirteen individuals who had volunteered to participate were purposely selected as respondents on the basis of their availability for interview and interest in the topic. Following completion of a consent form, participants were requested to complete the Revised Two-Factor Study Process Questionnaire (R-SPQ-2F) and to engage in a semi-structured interview of approximately 45 minutes. The participants' surface, deep or no strong learning preferences as predicted by the R-SPQ-2F are used as a benchmark against which to compare the results of the semi-structured interviews. Both forms of data collection were completed following submission of the assessment item and return of assessment outcomes.

\section{Revised Two-Factor Study Process Questionnaire (R-SPQ-2F)}

Using a five-point Likert scale the R-SPQ-2F is composed of 20 items. Ten items are predictors of a deep learning preference and ten are predictors of a surface preference. Where the participant has a strong bias for either a surface or deep learning preference they are likely to select the responses D (this item is frequently true of me) or E (this item is always or almost always true of me). Where the participant is ambivalent towards the preference addressed they are likely to select the response $\mathrm{C}$ (this item is true of me about half the time). Where the participant has a weak preference for the strategy addressed by the item they are likely to select response B (this item is sometimes true of me) or A (this item is never or rarely true of me) (Table 2).

Table 2: Likert scale responses to the R-SPQ-2F

\begin{tabular}{|c|c|l|}
\hline $\begin{array}{c}\text { Alphabetical } \\
\text { response }\end{array}$ & $\begin{array}{c}\text { Numerical } \\
\text { value }\end{array}$ & \multicolumn{1}{c|}{ Descriptive meaning } \\
\hline A & 1 & this item is never or only rarely true of me \\
\hline B & 2 & this item is sometimes true of me \\
\hline C & 3 & this item is true of me about half the time \\
\hline D & 4 & this item is frequently true of me \\
\hline E & 5 & this item is always or almost true of me \\
\hline
\end{tabular}

Whereas some other learning style inventories provide guidance on what constitutes a strong, moderate or weak preference, our survey of the literature related to the R-SPQ- 
$2 \mathrm{~F}$ was unsuccessful in revealing such guidance. As a result the participant's preference towards deep or surface learning in this research was interpreted using two approaches. Firstly, the ratio of summed scores were calculated by the addition of responses to questions related to deep and surface learning respectively where $A=1$. $B=2, C=3 . D=4$ and $E=5$ (Table 2). The greater the differential between the deep and surface learning scores, the greater the strength of the preference. Where the differential between surface and deep scores is small the preference for either learning approach is weak, the participant has no strong bias. Secondly, the distribution of responses across the questions that are concerned with deep and surface learning preference was considered. The greater the number of responses rated as D or E the stronger the preference towards the surface or deep learning preference being addressed.

\section{Semi-structured interviews}

Semi-structured interviews were conducted with each respondent following the completion of the multimedia assessment item and the R-SPQ-2F. Six questions were designed to elicit the participant's own understandings of their learning preference, the remaining four questions related to their approach to the completion of the multimedia assessment item. Prior to the interview, participants were provided with a description of the characteristics of surface and deep learners, which was used as a reference point for participants to describe their own learning preference (Table 1). Whilst providing a common language for discussion, this strategy increased the likelihood that participants might provide what they saw as 'appropriate responses'. To maximise the possibility that participants provided responses that reflected their personal behaviours rather than what they perceived to be an acceptable or appropriate response, they were also asked to expand on and justify their responses by providing examples of their preferred behaviours.

Questions relating to the participants learning preference were:

- How would you describe yourself as a learner? Explain please.

- Do you classify yourself as being a deep or surface learner?

- Has being involved in this assessment task had an impact on your learning habits? In what ways? Can you give me some examples?

- What type/s of assessments do you prefer and why?

- Were there any other factors that influenced your approach to the multimedia assessment?

Questions related to each participant's approach to completion of the multimedia assessment item were:

- How would you describe the experience of using the technology required for the multimedia assessment?

- Do you consider yourself a confident person when it comes to technology? Please explain.

- What did you like about the multimedia assessment and why?

- What didn't you like about the multimedia assessment and why not?

- Has there been any ongoing involvement with multimedia assessment?

In some cases the responses of participants were quite explicit in indicating whether they adopted a surface or deep learning style. For example: 'Yes, I'm a surface/deep 
learner'. In other cases the respondent might not be so explicit. However, when they describe their preferred learning approach the surface or deep preference can be interpreted. For example, comments such as: 'I need to try to understand what is going on'; 'knowing how things work isn't enough for me'; or, 'I also need to know why', would indicate a preference for a deep learning style. Comments such as: 'I look at how much the assessment is worth and then decide how much work to put in'; or, 'I only put in the amount of work that is needed', indicate a surface learning preference.

\section{Findings and discussion}

The respondent group consisted of eleven females and two males. Ages ranged from 19 to 25 years old. All of the females who participated were either 19 or 20 years old, the two males were 23 and 25 years old. This age and gender mix is typical for students in the second year of the Diploma of Events Management. In this report, pseudonyms are used.

\section{Revised Two-Factor Study Process Questionnaire (R-SPQ-2F) results}

The numerical responses of each participant to the R-SPQ-2F questions are found in Table 3, total scores and predicted learning preference in Table 4 . These show that the respondents predicted learning approach falls into three groups: dominant deep learning preference; non-dominant deep/surface learning preference; and dominant surface learning preference.

Table 3: R-SPQ-2F results

\begin{tabular}{|c|c|c|c|c|c|c|c|c|c|c|c|c|c|c|c|c|c|c|c|c|}
\hline \multirow[b]{2}{*}{ Student } & \multicolumn{10}{|c|}{ Deep preference questions } & \multicolumn{10}{|c|}{ Surface preference questions } \\
\hline & 1 & 2 & 5 & 6 & 9 & 10 & 13 & 14 & 17 & 18 & 3 & 4 & 7 & 8 & 11 & 12 & 15 & 16 & 19 & 20 \\
\hline Ruth & 4 & 5 & 4 & 4 & 5 & 5 & 5 & 4 & 5 & 4 & 1 & 3 & 1 & 1 & 1 & 1 & 1 & 1 & 1 & 1 \\
\hline Steph & 4 & 5 & 5 & 4 & 4 & 5 & 4 & 4 & 4 & 4 & 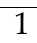 & 3 & 1 & 1 & 1 & 1 & 1 & 2 & 2 & 2 \\
\hline Fiona & 5 & 4 & 5 & 5 & 4 & 4 & 4 & 4 & 4 & 3 & 1 & 2 & 1 & 2 & 1 & 2 & 1 & 2 & 1 & 2 \\
\hline Jess & 4 & 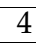 & 4 & 5 & 4 & 4 & 4 & 3 & 3 & 4 & 1 & 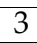 & 1 & 2 & 1 & 2 & 2 & 2 & 2 & 2 \\
\hline Lisa & 4 & 4 & 5 & 4 & 4 & 4 & $\overline{4}$ & 3 & 3 & 2 & 7 & 2 & 1 & 2 & 2 & 2 & 1 & 2 & 2 & 2 \\
\hline Sari & 4 & 4 & 4 & 4 & 4 & 3 & 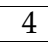 & 3 & 3 & 3 & 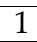 & 2 & 1 & 2 & 2 & 2 & 1 & 3 & 2 & 2 \\
\hline Ama & 3 & 3 & 3 & 3 & 3 & 2 & 4 & 2 & 3 & 4 & 3 & 2 & 4 & 3 & 3 & 3 & 2 & 3 & 2 & 3 \\
\hline Lanie & 2 & 3 & 3 & 3 & 3 & 3 & 2 & 3 & & 4 & & 3 & 1 & 3 & 2 & 3 & 2 & 3 & 3 & 3 \\
\hline Jasm & 2 & 3 & 3 & 2 & 3 & 3 & 3 & 2 & 2 & 2 & 3 & 2 & 5 & 4 & 2 & 3 & 5 & 3 & 3 & 3 \\
\hline Kylie & 2 & 1 & 2 & 2 & 2 & 3 & 4 & 2 & & 2 & 4 & 4 & 2 & 3 & 3 & 3 & 3 & 4 & 3 & 3 \\
\hline $\mathrm{Bec}$ & 1 & 2 & 2 & 2 & 2 & 3 & 1 & 1 & & 1 & 4 & 4 & 2 & 3 & 4 & 3 & 3 & 4 & 4 & 5 \\
\hline Jake & 1 & 2 & 1 & 2 & 2 & 3 & 4 & 1 & 2 & 1 & 4 & 5 & 2 & 3 & 3 & 3 & 3 & 4 & 4 & 3 \\
\hline Michael & 1 & 1 & 2 & 2 & 1 & 2 & 1 & 2 & 1 & 1 & 4 & 4 & 1 & 5 & 4 & 4 & 3 & 4 & 5 & 5 \\
\hline
\end{tabular}

The results of the R-SPQ-2F indicate that six participants (Ruth, Stephanie, Fiona, Jess, Lisa, Sari) have a preference towards a deep learning approach. In all six cases the deep learning preference score is at least twice the score for surface learning with a minimum numerical differentiation of 18 . Ruth and Stephanie scored all questions related to a deep preference as either D (frequently true of me), or E (always or almost always true of me). Fiona, Jess and Sari rated all responses to questions related to deep preferences as either D (frequently true of me), E (always or almost always true of me), or C (true of me about half the time). Lisa was the only respondent in this group in recording a single item related to a deep learning preference as B (sometimes true of me). In contrast, all six respondents recorded the majority of responses to questions related to a surface learning preference, as either A (never or only rarely true of me) or B (sometimes true of me) with Ruth, Stephanie and Jess rating a single item related to a 
surface learning preference as $C$ (true of me about half the time). In no case was a surface preference question rated as D (frequently true of me) or E (always or almost always true of me).

Table 4: R-SPQ-2F scores and predicted learning preference

\begin{tabular}{|l|c|c|c|}
\hline \multicolumn{1}{|c|}{ Student } & $\begin{array}{c}\text { Total deep } \\
\text { preference score }\end{array}$ & $\begin{array}{c}\text { Total surface } \\
\text { preference score }\end{array}$ & $\begin{array}{c}\text { Predicted learning } \\
\text { preference }\end{array}$ \\
\hline Ruth & 45 & 12 & Deep \\
\hline Stephanie & 43 & 15 & Deep \\
\hline Fiona & 42 & 15 & Deep \\
\hline Jess & 39 & 18 & Deep \\
\hline Lisa & 37 & 17 & Deep \\
\hline Sari & 36 & 18 & Deep \\
\hline Amanda & 29 & 26 & Non-dominant \\
\hline Lanie & 28 & 25 & Non-dominant \\
\hline Jasmine & 25 & 33 & Surface \\
\hline Kylie & 22 & 32 & Surface \\
\hline Bec & 20 & 36 & Surface \\
\hline Jake & 19 & 34 & Surface \\
\hline Michael & 14 & 39 & Surface \\
\hline
\end{tabular}

The responses of two participants (Amanda, Lani) do not show a strong preference for either a deep or surface learning. In both cases the differential between total deep and surface learning preference scores is three. In addition, the strongest response to any of the 20 questions was $C$ (true about half the time). There was not a single response of $D$ (frequently true of me), or E (always or almost always true of me) for either Amanda or Lani.

The results of the five remaining participants (Jasmine, Kylie, Bec, Jake, Michael) indicate a preference for a surface learning approach. In all six cases the surface learning preference score is at least one-third greater than the deep learning preference score with a minimum numerical differentiation of eight. In this sub-group, the great majority of responses to questions related to a deep learning preference were rated as A (never or only rarely true of me), B (sometimes true of me) or C (true of me about half the time). Only Kylie and Bec recorded a response of D (frequently true of me) to a single item related to a deep learning preference. In contrast, all respondents in this subgroup rated at least three questions related to a surface learning preference as either (frequently true of me) or E (always or almost always true of me).

\section{Semi-structured interview responses}

This section of the report is organised around the three groups that emerged from the completion of the R-SPQ-2F. That is: predicted preference for deep learning (Ruth, Stephanie, Fiona, Jess, Lisa, Sari); no strong predicted preference for either deep or surface learning (Amanda, Lani); and predicted preference for surface learning (Jasmine, Kylie, Bec, Jake, Michael).

\section{Predicted deep learning preference}

At interview, four of the six participants in this group (Ruth, Stephanie, Fiona, Jess) were clear in articulating their self-declared learning approach as consistent with a preference for deep learning. This group made reference to a preference for solving problems and a need to know why. 
I prefer to work through problems, rather than just getting the teacher to fix my problems for me. You don't learn that way. (Ruth)

Yes, I am a deep learner - I need to know why. (Stephanie)

I am not good at rote learning -I am probably a deep learner. (Fiona)

I have to know why. The more I can find out about my study the happier and more confident I feel. (Jess)

When asked how they had approached the multimedia assessment item, these four respondents suggested that this was also consistent with a preference for deep learning.

I need to go deep into the assessment in order to feel happy about doing a good job. I did this with the [multimedia assessment]. I like to know what's going on. (Ruth)

For me it was important that I understood exactly what was involved with the assessment. (Stephanie)

I tend to have a creative approach to my work. I like to see how I can use my own experience and creative skills for college work ... I think my assessment ... had a depth and quality that showed that I cared about my work. (Fiona)

For the multimedia assignment I really had to do some background study. I don't like it if I don't have all the information about the topic. (Jess)

The remaining two participants in this group (Lisa, Sari) were more reluctant to describe themselves as having a strong preference for one particular learning approach. Both expressed their dislike of labels and categories that were used to classify people. They considered themselves to be free agents who rejected these types of stereotypes. However, when asked questions related to how they had approached the multimedia assessment item, both participants described characteristics that are consistent with a deep learning approach. For example:

My approach to this assessment was the same for most of my work - do the background work, find the information and make sure that I had questions to ask if I couldn't find the answer myself. (Lisa)

I am a patient person who likes to get the work done. That way my work is better and more professional, rather than rushing and trying to get it over and done with. (Sari)

In summary, of the six cases where the R-SPQ-2F predicted a preference for a deep learning approach, four respondents self-declared a preference for deep learning at interview. When asked about the approach that they had adopted in completing the multimedia assessment item, their behaviour was also consistent with a deep learning approach. The remaining two respondents whose R-SPQ-2F had predicted a preference for deep learning were reluctant to declare a distinct preference at interview. However, when asked about their approach to completion of the multimedia assessment item, their description is again consistent with a deep learning approach. These findings suggest that, where learners have a distinct preference for deep learning, the implementation of a multimedia assessment item is not inconsistent with a deep learning approach. 


\section{Predicted surface learning preference}

The R-SPQ-2F predicts that five participants have a preference towards a surface learning approach (Jasmine, Kylie, Bec, Jake, Michael). At interview four of these five participants described themselves as having a surface preference (Jasmine, Bec, Jake, Kylie). Alternatively, Michael describes a deep learning preference that reveals a dissonance between the results of the learning preference questionnaire (R-SPQ-2F) and interview response.

In response to questions about their general approach to learning, Jasmine, Kylie, Bec and Jake made reference to skimming over content and only doing enough work to complete the required assessment. Jasmine, Bec and Kylie all qualified their response by indicating that they were more likely to spend more time on a topic that they found interesting. Most of the time though I am happy just to do enough to get by with - it's no real big
deal. (Jasmine)

I think I am a surface learner. I really only do enough work to get the assessment done so that I can hand it in. (Bec)

I tend to skim over things instead of spending more time and effort. It's part of how I learn and get through the work. (Kylie)

I always look at how much the work is worth which helps me to decide how much work to put in. (Jake)

In talking about the completion of the multimedia assessment item this group talked about only spending time on work that was assessable, doing just enough to get by and trying to complete their course as quickly as possible - all characteristics of a surface learning approach. Where Jasmine, Bec, Kylie and Jake show a consistency across all three data sets (R-SPQ-2F, self-declared learning preference and approach to the multimedia assessment item) this is not the case for Michael.

At interview, Michael, whose R-SPQ-2F predicted a preference for surface learning describes himself as having a deep learning preference, the way that he approached the completion of the multimedia assessment is also consistent with deep learning behaviours. Michael's interview provides some guidance in explaining the apparent dissonance (Case \& Marshall, 2009) between his predicted and implemented learning approaches in the Diploma of Events Management generally and the completion of the multimedia assessment specifically. Michael explains that he sees his future in the events management industry and is keen to finish his course. At 25 years old, Michael is the oldest of the respondent group and attributes this ambition to a growing maturity. He says 'at my age I don't want to muck around so I want to get the best marks'. Michael's view is consistent with the strategic approach to learning (Case \& Marshall, 2009; Entwistle, 1981) which aims at achieving a high level of performance using both surface and deep learning strategies depending on the circumstance.

In summary, in five cases the R-SPQ-2F indicates a distinct preference for surface learning. Four of these respondents' self-declared approach to learning and their approach to the completion of the multimedia assessment are also consistent with a surface learning approach. In contrast, Michael, whose R-SPQ-2F suggested the strongest preference towards a surface learning approach self-describes his learning 
approach in the Diploma of Events Management generally, and his approach to the multimedia assessment specifically as more consistent with deep learning behaviours. This apparent dissonance between the predicted and enacted learning behaviours may be explained by his desire to develop a career in events management. That is, adopting deep learning behaviours is a strategic choice in supporting the achievement of his career goals.

Together, the data associated with the group predicted to have a preference for surface learning suggest that, where the implementation of a multimedia assessment item does not prohibit behaviours that are consistent with a surface learning approach. Michael's case suggests that where the R-SPQ-2F indicates a surface learning preference, the implementation of a multimedia assessment item does not prohibit the adoption of a deep learning approach.

\section{Predicted non-dominant learning preference}

Responses to the R-SPQ-2F suggest that two participants (Amanda, Lanie) have no strong preference for either surface or deep learning. At interview, Amanda describes herself as a deep learner. For example

I am a deep rather than surface learner - I need to know why ... It certainly is important to try and learn and understand things by going deeper into the problem or question to be answered. (Amanda)

Lanie is more reluctant to declare herself as having a strong bias towards surface or deep learning.

I'm somewhere in the middle. I think I am a bit of both - deep and surface, depending on the task and if I am interested in the topic. If I don't like the topic then I think I would use a surface approach. But for hands on subjects I think I use a deep approach, and for theory subjects I use a surface approach and I would do the minimal work done. (Lanie)

When asked about their approaches to the completion of the multimedia assessment item, both describe characteristics that are more consistent with deep than surface learning.

I like the fact that you learned along the way especially when you collected the photos of the workplace and put them together, you had to understand the importance of the photos when you did the voice over and this gave me a better understanding of the topic rather than just doing a written assignment ... (Amanda)

The [multimedia assessment] gave you time to edit it and spend time on the quality issue. I like to spend time on things especially assessments. The more effort you put in the more you understand what you are learning. (Lanie)

In summary, two respondents to the R-SPQ-2F fail to identify a strong preference for either deep or surface learning. At interview Amanda self-describes her preferred approach to learning as consistent with deep learning whereas Lanie appears to be more strategic in adopting either a surface or deep approach depending on her level of interest in the specific topic and the nature of the assessment activity. When asked about the approach to the completion of the multimedia assessment item, both participants suggest that they have adopted strategies consistent with a deep learning approach. These findings suggest that, where learners do not have a strong preference 
for either surface or deep learning, the implementation of a multimedia assessment item does not prohibit the adoption of deep learning behaviours.

\section{Additional findings}

The data gathered also provides some clues related to the sorts of factors that the respondents considered and how they responded to these factors in completion of the multimedia assessment item. To this point, the participants' motivations for completing the Diploma in Events Management and their level of personal interest in the subject have been identified.

In addition, ten of the thirteen participants indicated that they had enjoyed completing the multimedia assessment item. This enjoyment would seem to be associated with the novelty of using the technology and the opportunity to be more creative than is typically the case with written assessment. Another contributing factor was the practical nature of the assignment and the explicit relationship to industry compared with other assessment that they perceive to be theoretical and intangible.

The remaining three respondents who indicated that they did not enjoy completing the multimedia assessment item cited their level of ability and comfort with the use of technology, and, the level of technical support available during completion as contributing factors. It is also observed that these three students were predicted to have a preference for a surface learning approach and adopted a surface learning approach in the completion of the multimedia assessment item. Given the limited nature of this research, no strong conclusion is drawn from this observation. However, in a general sense, these findings reinforce the importance of intrinsic and extrinsic factors in the individual's response to the implementation of a multimedia assessment item and reflects the models described by Biggs et al., (2001) and Ramsden (cited in Richardson, 2004).

\section{Conclusion}

This research aimed to test the proposition that the integration of a multimedia assessment activity in a Diploma of Events Management program might promote a deep learning approach. The research found that the use of the revised two-factor Study Process Questionnaire (R-SPQ-2F) (Biggs et al., 2001) provided a useful basis for discussion about learner's approaches to study and a comparison between predicted, self-declared and enacted learning behaviours in completing a multimedia assessment item.

In all six cases where the R-SPQ-2F predicted a preference for deep learning behaviours these were adopted in completion of the multimedia assessment item. In the two cases where the R-SPQ-2F predicted that the respondent had no strong preference for either surface or deep learning, both respondents adopted a deep learning approach in completion of the multimedia assessment item. In the five cases where the R-SPQ-2F predicted a surface learning preference, four respondents adopted surface learning behaviours in the completion of the multimedia assessment item. In one case where the R-SPQ-2F predicted a surface learning preference, the respondent self-described the completion of the multimedia assessment item as consistent with deep learning behaviours. In this case of dissonance, the respondent would appear to have adopted a strategic approach to learning assessment. 
These results do not provide adequate evidence to support the proposition that multimedia assessment promotes deep learning. Rather, it would appear that the multimedia assessment item enabled the adoption of both deep and surface learning approaches as determined by the learner. The results of interviews also provide some guidance on the range of factors that contribute to the learner's enacted approach. In each of the cases reported here, those respondents who prefer and adopt a surface learning approach would appear to be both conscious of, and comfortable with their approaches to learning. For us as practitioners, this finding has raised questions about our right as teachers to inadvertently disadvantage learners who choose to adopt a surface learning approach in our quest to universally promote deep learning.

\section{References}

Bauerlein, M. (2006). A very long disengagement. Chronicle of Higher Education, 52(18), 6.

Becker, K., Kehoe, J. \& Tennant, B. (2007). Impact of personalised learning styles on online delivery and assessment. Campus-wide Information Systems, 24(2), 105-119.

Bennett, S., Maton, K. \& Kervin, L. (2008). The 'digital natives' debate: A critical review of the evidence. British Journal of Educational Technology, 39(5), 775-786.

Biggs, J., Kember, D. \& Leung, D. (2001). The revised two-factor Study Process Questionnaire. British Journal of Educational Psychology, 71, 133-149.

Case, J. \& Marshall, D. (2009). Approaches to learning. In M. Tight (Ed.), The Routledge international handbook of higher education (pp. 9-21). Hoboken: Routledge.

Coffield, F., Moseley, D., Hall, E. \& Ecclestone, K. (2004). Should we be using learning styles? What research has to say to practice. London: Learning and Skills Development Agency. [verified 8 Dec 2010] https: / / crm.lsnlearning.org.uk/ user / order.aspx?code $=041540 \& s r c=X O W E B$

Cope, C. \& Staehr, L. (2005). Improving students' learning approaches through intervention in an information systems learning environment. Studies in Higher Education, 30(2), 181-197.

Cox, A., Vasconcelos, A. \& Holdridge, P. (2008). Diversifying assessment through multimedia creation in a non-technical module: Preliminary considerations for the MAIK project. Paper presented at the 9th Annual Conference of the Subject Centre for Information and Computer Sciences, Liverpool Hope University, 26-28 August.

Doumani, T. (2008). Implications of learning style preferences for training design in a banking workplace: A generational perspective. Unpublished Minor Thesis, RMIT University, Melbourne.

Entwistle, N. (1981). Styles of learning and teaching. New York: John Wiley \& Sons.

Jay, R. \& Connors, L. (2005). Using digital storytelling in VET. Experiences and reflections. Paper presented at the Learning Powerhouse, TAFE NSW ICVET Conference papers, Sydney, 15-16 September.

Kajder, S. \& Swenson, J. (2004). Digital images in the language arts classroom. Learning $\mathcal{E}$ Leading With Technology, 31(8), 18-19, 21, 46.

Kennedy, G., Judd, T., Churchward, A., Gray, K. \& Krause, K.-L. (2008). First year students' experiences with technology: Are they really digital natives? Australasian Journal of Educational Technology, 24(1), 108-122. http:/ / www.ascilite.org.au/ajet/ajet24/kennedy.html

Kvavik, R. (2005). Convenience, communications, and control: How students use technology. In D. Oblinger \& J. Oblinger (Eds.), Educating the Net Generation (pp. 7.1-7.20): EDUCAUSE. http: / / www.educause.edu/educatingthenetgen 
Lindblom-Ylanne, S. (2003). Broadening an understanding of the phenomenon of dissonance. Studies in Higher Education, 28(1), 63-77.

Marton, F., \& Saljo, R. (1976a). On qualitative differences in learning: I - outcome and process. British Journal of Psychology, 46(4), 4-11.

Marton, F., \& Saljo, R. (1976b). On qualitative differences in learning: II - outcome as a function of the learners conception of the task. British Journal of Psychology, 46(4), 115-127.

McGrath, P. \& Patetl, H. (2002). Our experiences with digital storytelling. Paper presented at Networking*2002, online, 4 December 2010.

http: / / pre2005.flexiblelearning.net.au/ projects / resources / Digital_Story_Telling.pdf

MCEETYA (2007). National assessment program - ICT literacy years $6 \mathcal{E} 10$ report 2005. Carlton South: MCEETYA. [verified 14 Dec 2010; 1.5 MB] http:/ / www.curriculum.edu.au/verve/ _resources/NAP_ICTL_2005_Years_6_and_10_Report.pdf

Mimirinis, M. \& Bhattacharya, M. (2007). Design of virtual learning environments for deep learning. Journal of Interactive Learning Research, 18(1), 55-64.

Moon, J. A. (2006). Learning journal. New York: Routledge.

Oblinger, D. \& Oblinger, J. (Eds.) (2005). Educating the Net Generation. EDUCAUSE. http:/ / www.educause.edu/educatingthenetgen

Ohler, J. (2009). The DAOW of literacy. [viewed 3 Mar 2009, verified 14 Dec 2010] http:/ / www.jasonohler.com/

Prensky, M. (2001). Digital natives, digital immigrants Part I. On The Horizon, 9(5), 1-6. http: / / www.marcprensky.com/writing/Prensky\%20\%20Digital\%20Natives, \%20Digital\%20Immigrants\%20-\%20Part1.pdf

Prensky, M. (2007). How to teach with technology: Keeping both teachers and students comfortable in an era of exponential change. Emerging Technologies for Learning (Vol. 2, pp. 4046). Coventry: BECTA. [verified 14 Dec 2010] http:/ / partners.becta.org.uk/page_docu ments / research/emerging_technologies07_chapter4.pdf

Ramsden, P. (1988). Improving learning: New perspectives. London: Kogan Page.

Richardson, J. (2004). Methodological issues in questionnaire-based research on student learning in higher education. Educational Psychology Review, 16(4), 347-358.

Sadik, A. (2008). Digital storytelling: A meaningful technology integrated approach for engaged student learning. Educational Technology Research \& Development, 56(4), 487-506.

Sadler-Smith, E. \& Smith, P. (2004). Strategies for accommodating individual's learning styles and preferences in flexible learning programmes. British Journal of Educational Technology, 35(4), 395-412.

Smith, P. \& Dalton, J. (2005). Accommodating learning styles: Relevance and good practice in vocational education and training. Adelaide: NCVER.

Woodward, H. \& Nanlohy, P. (2004). Digital portfolios: Fact or fashion? Assessment \& Evaluation in Higher Education, 29(2), 227-238.

Simon Hamm, William Angliss Institute, 555 La Trobe Street, Melbourne Vic 3000.

Email:simonh@angliss.edu.au

Dr Ian Robertson, RMIT University, GPO Box 2476, Melbourne Vic 3001.

Email: ian.robertson@rmit.edu.au 